\title{
DESAIN INTERAKSI SMART MOUSE UNTUK UBIQUITOUS HEALTH MONITORING SYSTEM
}

\author{
Nina Lestari \\ Program Studi Teknik Elektro \\ Universitas Sangga Buana YPKP Bandung \\ nina.lestari@yahoo.co.id
}

\begin{abstract}
Abstrak
Desain interaksi adalah membangun suatu produk yang mudah untuk dipelajari, efektif digunakan, dan terasa nyaman bagi penggunanya. Perencana desain interaksi memerlukan pengetahuan tentang pengguna, teknologi dan interaksi antara keduanya. Dengan mengetahui aktivitas dapat diketahui tipe interaksi dan jenis alat interaksi yang digunakan.

Ubiquitous health monitoring system adalah sebuah sistem pemantauan kesehatan yang digunakan oleh pengguna perseorangan untuk memantau kesehatannya terus menerus secara tidak sadar. Smart mouse merupakan salah satu perangkat yang digunakan pada ubiquitous health monitoring system. Pada mouse ini diterapkan teknologi tambahan untuk mengukur detak jantung dan suhu tubuh. makalah ini memberikan hasil desain berupa model konseptual, prototype, user experience, usability, user interface dari smart mouse.
\end{abstract}

Kata kunci : desain interaksi, model konspetual, user experience, usability, user interface, smart mouse, ubiquitous health monitoring system

\section{Pendahuluan}

Ubiquitous health monitoring system merupakan sistem pemantauan kesehatan yang sedang dikembangkan agar kesehatan dapat dipantau secara terus menerus sehingga dapat memberikan peringatan dini bagi penggunanya apabila ada hasil pemantauan yang tidak normal. Sistem ini terdiri dari beberapa bagian penting yaitu sensor dan komputasi yang diintegrasikan dengan berbagai peralatan yang biasa digunakan oleh pengguna, mikrokontroler sebagai penghubung antara sensor dengan komputer, server sebagai media penyimpanan data hasil pemantauan dan berbagai aplikasi sebagai user interface bagi pengguna sebagai media untuk mendapatkan tanggapan dari penggunaan sistem ini.

Sensor dan sistem komputasi yang diintegrasikan dengan berbagai peralatan yang biasa digunakan oleh pengguna sehingga keberadaannya tidak disadari oleh pengguna. Sensor ini akan berfungsi dengan menggunakan interface yang lebih alami seperti sentuhan, deteksi gerakan atau yang lainnya.

Desain interaksi sebagai suatu proses untuk mencapai suatu tujuan dengan pencarian berbagai solusi melalui ruang lingkup sistem, materi, biaya dan kemungkinan penyelesaiannya (feasibilitas), sebagai wujud kreativitas dan pengambilan keputusan untuk menyeimbangkan trade-off. Selain itu desain interaksi merupakan representasi suatu perencanaan pengembangan yang berisikan sekumpulan elaborasi alternatif dan suksesif.

Pada ubiquitous health monitoring system terdapat berbagai sensor yang diintergrasikan dengan berbagai benda yang biasa digunakan oleh pengguna di rumah, kantor ataupun kendaraan. Benda yang biasa digunakan oleh pengguna yang akan dibahas pada makalah ini adalah mouse. Mouse merupakan sebuah alat bantu teknologi yang sering digunakan oleh manusia di rumah atau di kantor ketika menggunakan komputer.

Sensor yang diintegrasikan pada mouse adalah sensor infrared untuk pengukuran detak jantung dan sensor suhu untuk mengukur suhu tubuh. Kedua sensor ini dipasangkan pada mouse tanpa mengubah fungsi awal mouse sehingga mouse tetap dapat digunakan seperti biasa dengan tambahan fungsi pengukuran detak jantung dan suhu tubuh. 
Metode yang digunakan untuk desain interaksi smart mouse ini adalah penelitian untuk melihat kebiasaan penggunaan mouse dan kemungkinan penerapan teknologi tambahan, pembuatan model konseptual, pembuatan prototype, implementasi dan pengujian. Seluruh tahapan ini dilakukan untuk membuktikan bahwa smart mouse memenuhi tujuan desain interaksi sebagai produk yang dapat digunakan.

\section{Desain Interaksi Smart Mouse}

Desain interaksi adalah merancang sebuah produk interaktif untuk membantu manusia dalam kehidupan dan pekerjaannya.[1] Desain interaksi berarti membangun suatu produk yang dapat digunakan yang artinya mudah untuk dipelajari, efektif digunakan, dan terasa nyaman bagi penggunanya. Dengan mengetahui aktifitas, maka akan diketahui tipe interaksi dan jenis alat interaksi yang digunakan. Perancang desain interaksi memerlukan pengetahuan tentang pengguna, teknologi dan interaksi antara keduanya untuk menciptakan pengalaman pengguna yang efektif. Desain interaksi diperlukan agar produk yang dihasilkan sesuai dengan kebutuhan pengguna dan memberikan user experience yang tepat. Memahami tujuan usability dan user experience sangat penting dalam pembuatan suatu produk sehingga produk mampu untuk memenuhi berbagai kebutuhan pengguna.

Proses desain interaksi dilakukan sesuai dengan aktivitas dasar, yaitu

1. Identifikasi kebutuhan dan menetapkan persyaratan.

2. Membangun desain untuk memenuhi persyaratan yang sudah dibuat.

3. Membangun versi interaktif dari desain sehingga mereka dapat dikomunikasikan dan dinilai.

4. Mengevaluasi apa yang sedang dibangun di seluruh proses.

Usability memegang peranan cukup besar agar sistem secara baik dapat diterima user dan seluruh pihak yang terkait dengan sistem. Tujuan usability adalah untuk memastikan bahwa produk yang dibuat mudah untuk dipelajari, efektif untuk digunakan dan menyenangkan menurut pandangan pengguna

Tujuan dari user experience adalah menciptakan produk yang menyenangkan, memuaskan dan estetis. Sehingga desain interaksi harus membuat sistem seperti kegiatan natural dari pengguna.
Model konseptual adalah deskripsi dari sistem yang diusulkan dalam sebuah ide dan konsep mengenai hal yang harus dilakukan, fungsi dan bentuk yang dibuat harus dimengerti oleh pengguna sesuai dengan peruntukannya.[1]

Sebagai bagian dari desain interaksi maka proses pembuatan model konseptual dilakukan berulang kali dengan mengunakan berbagai metode. Proses pengulangan ini termasuk pembuatan ide, alur cerita, skenario penggunaan produk, dan pembuatan protoype produk.

Prototype adalah sebuah contoh atau model yang dibuat untuk menguji sebuah konsep atau proses dari desain. Hal ini dilakukan untuk menguji serta mencoba sebuah desain baru dan memastikan bahwa produk yang dibuat akan berkerja sesuai dengan yang dirancang.[4]

Prototype merupakan aspek penting dalam sebuah proses desain. Prototype dibuat dengan tujuan untuk mendapatkan hasil evaluasi dan umpan balik dari pembuatan suatu produk.

Ubiquitous adalah sesuatu yang berada dimana saja [4]. Dalam kaitan dengan teknologi, ubiquitous berarti teknologi yang bisa diterapkan dimana saja.

Sistem ini terdiri dari berbagai peralatan dan jenis pengguna. Peralatan tersebut diintegrasikan pada peralatan yang biasa digunakan di rumah, kantor dan kendaraan. Informasi hasil pemantauan kesehatan tersebut dapat digunakan oleh pengguna perseorangan, dokter, rumah sakit, apotik dan komunitas.

Tanda kesehatan yang dipantau adalah tanda- tanda vital yang terdiri dari detak jantung, tekanan darah, respirasi dan suhu tubuh.[6] Pemantauan tersebut dilakukan dengan berbagai sensor yang diintegrasikan pada berbagai peralatan yang sering digunakan oleh pengguna. Hasil pemantauan akan disimpan pada server yang akan dapat diakses oleh pengguna, tenaga medis dan komunitas.

Smart mouse merupakan bagian dari ubiquitous health monitoring system. Smart mouse digunakan untuk pemantauan suhu tubuh dan detak jantung dengan menggunakan sensor inframerah dan sensor panas. Hasil pembacaan suhu tubuh dan detak jantung ini akan diolah oleh arduino sebagai mikrokotroler yang dapat diprogram melalui komputer.

\section{Desain Sistem Smart Mouse}

Membuat model konseptual produk memerlukan identifikasi kebutuhan dan 
persyaratan dari pengguna. Aspek utama dari proses desain adalah memutuskan hal yang akan dilakukan oleh pengguna dengan produk yang dibuat. Model konseptual dibuat sebagai solusi akan kebutuhan pengguna terhadap sebuah produk dengan memperhitungkan kebiasaan alami dari pengguna.

Smart mouse dirancang setelah mengidentifikasi kebutuhan dari pengguna, diantaranya adalah :

- Kebutuhan terhadap alat pemantau kesehatan yang mudah digunakan dan dimengerti oleh pengguna awam.

- Kebutuhan pengguna terhadap alat pemantau kesehatan tanpa meninggalkan pekerjaan yang sedang dilakukan.

- Kebutuhan terhadap alat pemantau kesehatan yang handly tanpa merubah kebiasaan dari pengguna.

Dari kebutuhan tersebut maka dapat dibuat kesimpulan bahwa persyaratan yang harus dipenuhi dalam perancangan smart mouse ini adalah :

- Mudah untuk digunakan.

- Murah

- Aman dan nyaman

- Tidak mengganggu kebiasaan pengguna pada saat menggunakan produk

Prototype smart mouse ini dilakukan melalui dua tahap pembuatan prototype, yaitu prototype dengan ketelitian rendah dan prototype dengan ketelitian tinggi. Pada prototype dengan ketelitian rendah dibuat perencanaan model smart mouse, skenario, dan simulasi sensor smart mouse dengan menggunakan software. Sedangkan pada prototype dengan ketelitian tinggi dibuat sebuah model mouse dengan membuat model smart mouse dengan tambahan sensor sesuai dengan perancangan.

Smart mouse dirancang tanpa membuat perubahan pada desain mouse yang sudah banyak digunakan oleh pengguna. Bentuk mouse tidak berubah meski sudah dilengkapi dengan sensor infrared dan sensor suhu seperti terlihat pada Gambar 3. 1

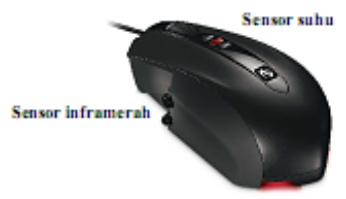

Gambar 1 : Rancangan model smart mouse
Desain skenario penggunaan smart mouse adalah sebagai berikut :

Sensor akan berfugsi ketika pengguna mulai memgang mouse sebagai alat bantu penggunaan komputer. Sensor akan berfungsi dengan adanya sentuhan dari pengguna.

Pada umumnya, pengguna akan menempatkan ibu jari pada bagian sensor inframerah seperti pada Gambar 3. 1 dan sensor suhu akan berada pada bagian telapak tangan dan mengalami interfensi minim dari suhu luar. Hasil pengukuran kedua sensor tersebut akan diolah dan dapat dibaca melalui aplikasi antar muka pada komputer. Data hasil ukur tersebut akan disimpan dan dikirimkan ke server untuk kemudian dapat disimpan sebagai rekam medis dari pengguna.

Teknik dalam pengukuran denyut jantung pada rangkaian yaitu dengan merasakan perubahan volume darah dalam arteri pada ujung jari saat jantung memompa darah. Rangkaian pengukur denyut jantung terdiri dari sebuah led inframerah yang mentransmisikan sinyal IR melalui jari, bagian dari yang tercermin oleh sel-sel darah. Perubahan kecil dalam amplitudo pantulan cahaya dapat diubah menjadi denyut nadi. Sinyal dipantulkan dan terdektesi dari sensor sebuah photodiode sebagai receiver, sinyal tersebut terlalu kecil untuk dapat dideteksi secara langsung oleh arduino sebagai mikrokontroler. Oleh karenanya, pada rangkaian dipasang 2 amplifier filter yang dirancang sebagai penguat operasional (op-amps) untuk menyaring dan memperkuat sinyal pada tegangan yang sesuai sehingga pulsa yang ditangkap oleh photodiode dapat dihitung oleh mikrokontroler. Intensistas cahaya yang dipantulkan tergantung pada volume darah di dalam ujung jari.

Sensor suhu DS18B20 yang merupakan sensor digital akan membaca suhu tubuh kemudian hasil pengukuran tersebut akan dikirmkan ke modul Arduino Nano. DS18B20 menggunakan library OneWire.h dan OneWire.cpp pada pemograman Arduino Nano.

Realisasi model smart mouse dilakukan dengan membuat rangkaian sensor pada PCB kemudian menguji rangkaian tersebut berjalan seperti yang disimulasikan di software simulator rangakaian 


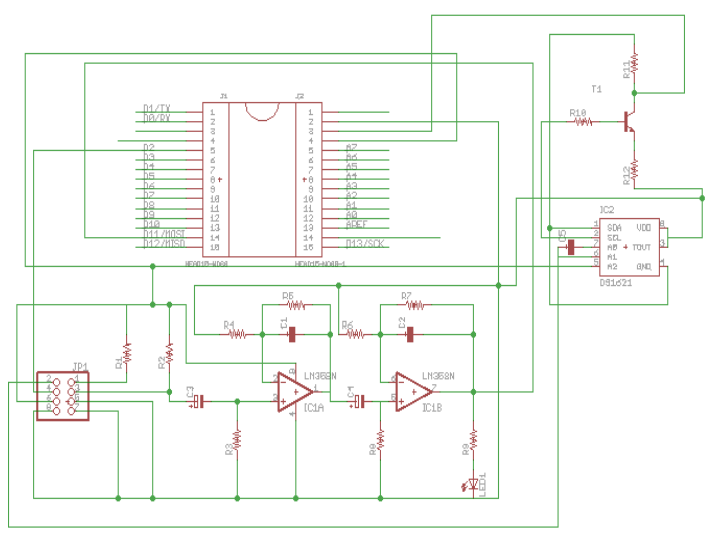

Gambar 2 : Rangkaian sensor smart mouse

Kedua rangkaian sensor smart mouse disesuaikan ukurannya dengan ukuran mouse normal supaya tidak merubah kebiasaan dari penggunaan mouse biasa.

Seperti terlihat pada Gambar 3.4, aplikasi antar muka smart mouse dimulai ketika penggguna menggunakan mouse dan mengaktikkan seluruh sensor yang ada pada smart mouse. Setelah semua sensor aktif, pengukuran yang pertama dilakukan adalah pengukuran detak jantung kemudian pengukuran suhu tubuh. Kedua data tersebut dikirim ke Arduino Nano yang kemudian terhubung dengan komputer. Hasil pengukuran detak jantung dan suhu tubuh akan tersimpan di komputer yang berfungsi sebagai local server. Data tersebut akan dikirim ke server dan dapat diakses dari web Ubiquitous Health Monitoring System.

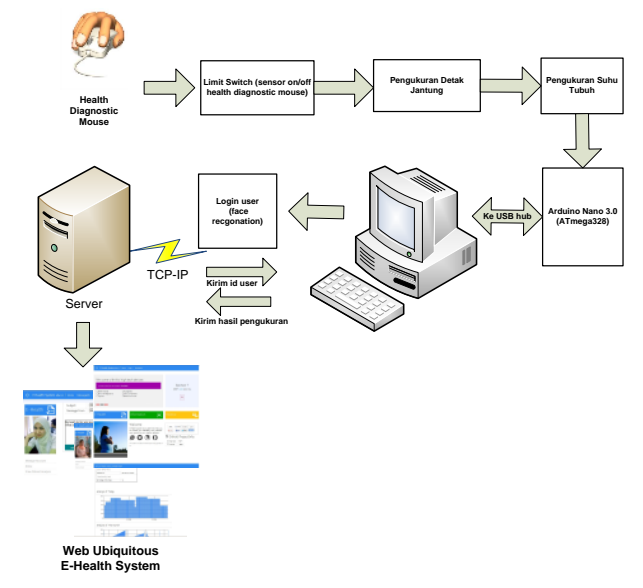

Gambar 3 : Diagram blok sistem kerja aplikasi

Data yang diterima pada aplikasi destop untuk selanjutnya akan dikirim ke server dalam bentuk byte. Untuk nilai suhu akan dikirim pada saat suhu stabil, yaitu setelah 40 kali kemunculan nilai yang sama.

\section{Pengujian}

Berdasarkan Gambar 3.1, smart mouse memenuhi seluruh identifikasi kebutuhan dan persyaratan dari pengguna. Smart mouse dirancang agar mudah digunakan oleh pengguna. Dua tanda vital yaitu detak jantung dan suhu tubuh dapat diukur tanpa harus meninggalkan pekerjaan dan hasilnya mudah dimengerti oleh pengguna. Penambahan sensor pada mouse tidak merubah kebiasaan pengguna pada saat beraktifitas dengan mouse.

\section{1. 1. Hasil simulasi rangkaian sensor}

Simulasi rangkaian sensor dilakukan dengan menggunakan Electronic Work Bench untuk menganalisis rangkaian amplifier yang digunakan pada sensor denyut jantung.

Setelah rangkaian amplifier tesebut disimulasikan dan dapat memberikan sinyal dengan tegangan yang dapat dibaca oleh mikrokontroler kemudian rangkaian sensor tersebut dibuat pada project board, Tabel 4.1 menunjukkan hasil pengukuran denyut jantung dengan menggunakan rangkaian sensor yang diukur pada ibu jari dan pengukuran denyut jantung manual dengan menggunakan jari yang diukur pada pergelangan tangan.

Pengukuran ini dilakukan pada 50 orang perempuan dan 50 orang laki-laki dengan variasi umur dari 20-50 tahun. Hasil perbandingan pengukuran sensor dengan pengukuran manual menunjukan bahwa terjadi perbedaan dengan nilai error $1.8 \%$. Nilai error ini muncul disebabkan oleh adanya interfensi cahaya dari luar yang diterima oleh sensor inframerah ketika pengguna mencoba rangkaian sensor tersebut karena ketidaktepatan penempatan ibu jari pada sensor inframerah.

Dengan kemunculan error itu dapat disimpulkan bahwa pengguna perlu memperhatikan intensitas cahaya diruangan dan memastikan bahwa ibu jari sebagai objek ukur harus diletakan dengan tepat pada sensor inframerah. 
Tabel 1 : Perbandingan hasil simulasi pengukuran denyut jantung rangkaian sensor dengan pengukuran manual

\begin{tabular}{|c|c|c|c|}
\hline No & $\begin{array}{c}\text { Jenis } \\
\text { Kelamin } \\
(\mathrm{L} / \mathrm{P})\end{array}$ & $\begin{array}{r}\text { Usia } \\
\text { (tahun) }\end{array}$ & $\begin{array}{l}\text { Rata- } \\
\text { rata error } \\
\%\end{array}$ \\
\hline 1 & $\mathrm{~L}$ & 21 & 1,18 \\
\hline 2 & $\mathrm{~L}$ & 25 & 1,25 \\
\hline 3 & $\mathrm{~L}$ & 33 & 1,13 \\
\hline 4 & $\mathrm{~L}$ & 44 & 1,24 \\
\hline 5 & $\mathrm{~L}$ & 51 & 3,65 \\
\hline 6 & $\mathrm{P}$ & 22 & 1,93 \\
\hline 7 & $\mathrm{P}$ & 27 & 0,94 \\
\hline 8 & $\mathrm{P}$ & 35 & 2,38 \\
\hline 9 & $\mathrm{P}$ & 47 & 1,36 \\
\hline 10 & $\mathrm{P}$ & 49 & 2,94 \\
\hline & \multicolumn{2}{|c|}{ Rata-rata error } & 1,8 \\
\hline
\end{tabular}

Tabel 2 : Perbandingan hasil pengukuran suhu tubuh dengan sensor suhu dan termometer digital

\begin{tabular}{|c|c|c|c|}
\hline No & $\begin{array}{c}\text { Jenis } \\
\text { Kelamin } \\
(\mathrm{L} / \mathrm{P})\end{array}$ & $\begin{array}{c}\text { Usia } \\
\text { (tahun) }\end{array}$ & $\begin{array}{c}\text { Rata- } \\
\text { rata error } \\
\%\end{array}$ \\
\hline 1 & $\mathrm{~L}$ & 21 & 2,83 \\
\hline 2 & $\mathrm{~L}$ & 25 & 2,64 \\
\hline 3 & $\mathrm{~L}$ & 33 & 3,65 \\
\hline 4 & $\mathrm{~L}$ & 44 & 2,67 \\
\hline 5 & $\mathrm{~L}$ & 51 & 4,83 \\
\hline 6 & $\mathrm{P}$ & 22 & 1,46 \\
\hline 7 & $\mathrm{P}$ & 27 & 2,38 \\
\hline 8 & $\mathrm{P}$ & 35 & 2,52 \\
\hline 9 & $\mathrm{P}$ & 47 & 2,89 \\
\hline 10 & $\mathrm{P}$ & 49 & 2,31 \\
\hline & \multicolumn{2}{|c|}{ Rata-rata error } & 2,818 \\
\hline
\end{tabular}

Hasil simulasi pengukuran suhu tubuh terlihat pada Tabel 4. 2. Pengukuran tersebut dilakukan kepada orang yang sama dengan pengukuran denyut jantung. Pada hasil pengukuran tersebut terlihat error sebesar $2,818 \%$. Sensor suhu bekerja membutuhkan waktu minimal 10 detik dalam keadaan pengguna diam. Ketika ada perubahan posisi maka akan terjadi perubahan suhu yang menyebabkan perbedaan dengan hasil pengukuran dengan menggunakan termometer digital

\section{Hasil aplikasi antar muka smart mouse}

Pengguna dapat menerima feedback dari penggunaan smart mouse melalui aplikasi antarmuka. Contoh tampilan hasil pengukuran ditunjukkan oleh Gambar 4.2

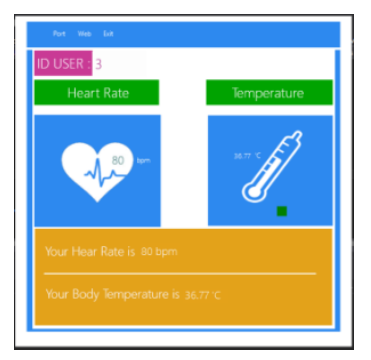

Gambar 4 : Tampilan hasil pengukuran denyut jantung dan suhu tubuh

\section{Analisis usability smart mouse}

Berdasarkan hasil prototype dapat dilihat bahwa smart mouse ini memenuhi ketentuan usability menurut Nielsen [2] bahwa sebuah produk harus memenuhi aspek learnability, efficiency, memorability, errors, dan satisfaction.

Tabel 3 : Hasil angket penggunaan prototype smart mouse

\begin{tabular}{|l|l|r|r|r|r|r|c|}
\hline $\mathrm{No}$ & $\begin{array}{c}\text { (L/P } \\
)\end{array}$ & $\begin{array}{c}\text { Usia } \\
\text { (tahu } \\
\mathrm{n})\end{array}$ & $\begin{array}{c}\text { Learnab } \\
\text { ility } \\
(1-5)\end{array}$ & $\begin{array}{c}\text { Effecie } \\
\text { ncy } \\
(1-5)\end{array}$ & $\begin{array}{c}\text { Memora } \\
\text { bility } \\
(1-5)\end{array}$ & $\begin{array}{c}\text { Erro } \\
\text { rs }\end{array}$ & $\begin{array}{c}\text { Satis } \\
\text { facti } \\
\text { on } \\
(1-5)\end{array}$ \\
\hline 1 & $\mathrm{~L}$ & 21 & 4 & 2 & 4 & 2 & 2 \\
\hline 2 & $\mathrm{~L}$ & 25 & 3 & 2 & 4 & 2 & 2 \\
\hline 3 & $\mathrm{~L}$ & 33 & 4 & 3 & 3 & 3 & 3 \\
\hline 4 & $\mathrm{~L}$ & 44 & 3 & 4 & 2 & 2 & 2 \\
\hline 5 & $\mathrm{~L}$ & 51 & 4 & 2 & 2 & 1 & 1 \\
\hline 6 & $\mathrm{P}$ & 22 & 4 & 3 & 4 & 3 & 2 \\
\hline 7 & $\mathrm{P}$ & 27 & 3 & 2 & 3 & 2 & 1 \\
\hline 8 & $\mathrm{P}$ & 35 & 2 & 4 & 3 & 3 & 3 \\
\hline 9 & $\mathrm{P}$ & 47 & 4 & 4 & 4 & 4 & 2 \\
\hline 10 & $\mathrm{P}$ & 49 & 3 & 3 & 2 & 2 & 1 \\
\hline
\end{tabular}

Keterangan : $1=$ tidak setuju $-5=$ setuju

Nilai pada Tabel 4.3 didapatkan setelah masing-masing pengguna mencoba menggunakan smart mouse sebanyak 20 kali pada berbagai variasi waktu. Dari tabel tersebut dapat dapat dilihat bahwa smart mouse memiliki nilai learnability yang tinggi, artinya pengguna dapat dengan mudah menggunakan smart mouse sejak awal penggunaan sistem.

Nilai terkecil diperoleh oleh satisfaction karena menurut para pengguna prototype smart mouse ini terlalu besar dan agak sulit untuk tidak merubah posisi tangan selama 10 detik 
yang merupakan waktu standar pengukuran pada smart mouse.

Effeciency dan memorability smart mouse memiliki nilai sedang dengan begitu dapat ditarik kesimpulan bahwa smart mouse ini dapat meningkatkan produktivitas dan mudah diingat ketika pengguna tidak menggunakan produk tersebut dalam waktu yang lama.

Nilai error yang muncul dapat diantisipasi dengan menggunakan pemograman pada mikrokontroler sehingga hasil pengukuran sensor dapat menjadi sama dengan hasil pengukuran manual.

\section{Analisis user experience smart mouse}

Tujuan dari pengujian user experience adalah menciptakan produk yang menyenangkan, memuaskan dan estetis. Sehingga desain interaksi harus membuat sistem seperti kegiatan natural dari pengguna. Dengan melihat pada Tabel 4. 3 dapat dilihat bahwa smart mouse dapat digunakan seperti pengguna menggunakan secara natural seperti menggunakan mouse biasa. Secara keseluruhan smart mouse ini dapat memenuhi tujuan user experience dari sebuah produk.

\section{Kesimpulan}

Desain interaksi smart mouse telah dibuat dan berhasil memenuhi kebutuhan sistem Ubiquitous Health Monitoring System. Seluruh prasayarat desain interaksi telah dilaksanakan pada pembuatan prototype smart mouse.

\section{Referensi}

[1] J. Preece, Interaction Design Beyond Human Computer Interaction. USA: John Wiley \& Sons, Inc, 2002.

[2] R. R. a. D. C. Alan Cooper, About Face 3 The Essentials of Interaction Design, 3rd ed. Indianapolis: Wiley Publishing, Inc., 2007.

[3] J. Nielsen. (1995, Jan.) NN Group. [Online]. http://www.nngroup.com/articles/tenusability-heuristics/

[4] (2012, May) PC Magazine. [Online]. http://www.pcmag.com/encyclopedia/term/4 9886/prototyping
[5] (2013, May) Dictionary. [Online]. http://dictionary.reference.com/browse/ubiq uitous

[6]D. L. a. M. F. O'Keefe, Emergency Care, 11th, Ed. Pearson, 2010.

[7] R. Febriani, "Rancang Bangun Health Diagnostic Mouse Pengukur Detak Jantung dan Suhu Tubuh Pada Ubiquitous Health Monitoring System," ITB, 2013.

[8] N. N. Sari, "Antarmuka komunikasi dan pengolahan data health diagnostic mouse pada ubiquitous health monitoring system," ITB, 2013. 